\title{
LA PLAZA DE LA ALFALFA DE SEVILLA EN EL SIGLO XIX: INTERVENCIONES URBANÍSTICAS Y PROYECTOS
}

\section{ALFALFA SQUARE IN SEVILLE IN THE $19^{\text {th }}$ CENTURY: URBAN INTERVENTIONS AND PROJECTS}

\author{
Alberto Fernández González \\ Universidad de Sevilla. España \\ ORCID: 0000-0003-1582-2464 \\ alberfer@us.es
}

La plaza de la Alfalfa se formó en el siglo XIX, aunque el espacio donde hoy se ubica desempeñó un relevante papel en la Sevilla romana. El artículo da a conocer las intervenciones urbanísticas realizadas a lo largo del ochocientos en el ámbito de la primitiva plazuela, que aparece reproducida en el plano de 1771 del asistente Olavide, y su entorno viario. Se analizan, por tanto, las alineaciones, los ensanches y los derribos proyectados por los arquitectos municipales con objeto de remodelar y configurar la plaza decimonónica. Para establecer su dilatada historia constructiva, se ha manejado documentación inédita conservada en el Archivo Histórico Municipal de Sevilla: informes técnicos, proyectos, levantamientos planimétricos, croquis y expedientes de obra pública.

Palabras clave: plaza de la Alfalfa; Sevilla; Urbanismo; siglo XIX; planos y proyectos.

Alfalfa Square was created in the $19^{\text {th }}$ century, but the place where it is currently located played a relevant role in Roman Seville. This paper shades light on the urban interventions carried out throughout the $19^{\text {th }}$ century in the original square and surrounding streets, which appeared drawn in a plan by assistant Olavide dating from 1771 . We have analysed the alignments, widening and demolitions devised by the local architects to refurbish and reshape the $19^{\text {th }}$ century square. In order to establish its long building history, we have used unpublished documents kept in Seville's Municipal Historical Archives: technical reports, projects, planimetric drawings, drafts and public building records.

Keywords: Alfalfa Square; Seville; urban planning; $19^{\text {th }}$ century; plans and projects.

La Alfalfa es una emblemática plaza del casco histórico de Sevilla en la que confluyen las calles Pérez Galdós, Guadarmino, San Juan, Odreros, Alfalfa, Jesús de las Tres Caídas, Ángel María Camacho y Alcaicería. Se conoce con este nombre, no obstante, desde 1980 porque la plaza, cuando se formó en 1837, 
alcanzando unas dimensiones parecidas a las actuales, era denominada de las Carnicerías Viejas, y con posterioridad, en la segunda mitad del ochocientos, fue dedicada primero al Infante Don Fernando y más tarde a Mendizábal, el famoso ministro de Isabel $\mathrm{II}^{1}$. El espacio donde hoy se ubica la plaza desempeñó un relevante papel en la Sevilla romana ya que en él interseccionaban el cardo máximo y el decumano máximo, siendo, por tanto, el lugar donde estaría situado el foro imperial de Hispalis ${ }^{2}$. El característico desarrollo orgánico del urbanismo islámico alteró en época musulmana este posible trazado regulador preexistente. Por ello, los conquistadores cristianos, a mediados del siglo XIII, se encontraron con una ciudad que respondía en gran medida a este tipo de estructura urbana espontánea así que, muy probablemente, la actual Alfalfa correspondería a un simple espacio donde confluían varias calles ${ }^{3}$. En todo caso, desde la conquista castellana de 1248 se intensificó el proceso de especialización de las plazas sevillanas, en consonancia con los usos bajomedievales, y cabe la posibilidad de que la primitiva plazuela de la Alfalfa albergase ya, con el paso del tiempo, pequeños puestos de carne y verduras que adquirieron progresivamente cierta relevancia comercial hasta acoger, ya en las últimas décadas del siglo XV, las principales carnicerías de la ciudad ${ }^{4}$.

Establecer los posibles cambios morfológicos del espacio hoy ocupado por la plaza de la Alfalfa es una difícil tarea. La investigación, si comprende un marco cronológico muy amplio, desde época romana, tendría que valorar datos arqueológicos, documentos históricos y referencias gráficas, y su multidisciplinario enfoque metodológico debería hacer frente a la limitación que supone la escasez de información y fuentes. Pero las transformaciones urbanísticas llevadas a cabo en el siglo XIX pueden ser abordadas, en gran medida, a la luz de la documentación custodiada en el Archivo Histórico Municipal de Sevilla. A este objetivo dedico el artículo, que es el primer trabajo específico que da a conocer y analiza los proyectos y las intervenciones directamente relacionados con la formación de la plaza en el ochocientos 5 .

${ }^{1}$ Una detallada información sobre las diversas denominaciones que recibió la plaza a lo largo de la historia en Collantes/Cruz/Reyes/Rodríguez, 1993: 58-59.

${ }^{2}$ Esta conocida hipótesis, que está avalada por la concentración de epígrafes honoríficos en la zona, fue establecida por Blanco Freijeiro, 1979: 131-133. Al respecto, véase también Campos, 1993: 198-199. Una revisión crítica de la hipótesis en González Acuña, 2011: 171-173.

3 Al respecto, véase Collantes de Terán Sánchez, 1977: 77.

${ }^{4}$ Montoto, 1983: 65. Collantes/Cruz/Reyes/Rodríguez, 1993: 58. En la primitiva plazuela de la Alfalfa, por lo menos en el siglo XVI, se vendían también aves vivas según De Peraza, 1996: 105.

${ }^{5}$ Que yo conozca, no existe ningún trabajo específico sobre la plaza de la Alfalfa de Sevilla. No obstante, algunos autores han realizado breves consideraciones al respecto: Vioque Cubero/Vera Rodríguez/López López, 1987: 30-31. Albardonedo Freire, 2002: 
El obligado punto de partida de la investigación no puede ser otro que el famoso plano de Sevilla delineado por Francisco Coelho y grabado por Joseph Amat que mandó realizar el asistente Pablo de Olavide en 1771 (Figura 1). Este importante documento gráfico reproduce, aproximadamente, el espacio que comprendía la primitiva plaza de la Alfalfa, situada justo al lado de la calle Alfalfa, que por error se denomina "Falfa". Muy reducida en sus dimensiones, la plazuela, que en ese momento albergaba el histórico mercado de forraje y hortalizas $^{6}$, se extendía desde las esquinas de las actuales calles Huelva y Odreros hasta la embocadura de la calle Alfalfa. El plano de Olavide describe el flanco oeste de la plaza, ocupado por un compacto caserío y la denominada "Carnicería Maior", edificio que fue proyectado en 1545, bajo el gobierno del asistente Pedro de Navarra $^{7}$, con el propósito de centralizar el abasto de carne de Sevilla, y que, según Alonso de Morgado $^{8}$, se organizaba en dos plantas en torno a un espacioso patio central, circunvalado a su vez por cuarenta y ocho puestos de venta. La planimetría de 1771 no detalla pormenorizadamente la estructura de la Carnicería Real, pero los dos accesos que recogen las fuentes aparecen perfectamente representados. Así pues, orientada hacia la contigua plazuela de las Berzas, que no era más que un pequeño espacio residual formado a la salida de la calle Alcaicería de la Loza, se constata la puerta oeste del histórico establecimiento comercial, y en directa comunicación con la primitiva plaza de la Alfalfa, la portada este. Aunque en el plano del asistente Pablo de Olavide no figuran, se sabe que en el centro de la plazuela se ubicaba una artística cruz de hierro ${ }^{9}$ y que en el frente de poniente estaba instalada la fuente pública que surtía al barrio con el agua canalizada proveniente de los Caños de Carmona ${ }^{10}$.

Apenas hay datos concretos sobre los edificios que circunvalaban la plazuela en los inicios del siglo XIX. La escasa documentación de archivo hallada permite constatar, eso sí, que las monjas de Santa Clara eran las propietarias de una vivienda allí situada ${ }^{11}$ y que el convento de San José poseía la titularidad de las

228. La aportación más relevante sobre la plaza es la de Collantes/Cruz/Reyes/Rodríguez, 1993: 58-59.

${ }^{6}$ El mercado se mantuvo hasta 1820. González de León, 1839: 18. Durante cuatro meses al año, los vecinos podían vender libremente el vino que habían introducido, razón por la que estaba muy cerca el hospital y la casa gremial de los vinateros. Montoto, 1983: 66.

${ }^{7}$ Albardonedo Freire, 2002: 69.

8 De Morgado, 1587: 52v.

9 La cruz, que estaba cercada por rejas, se elevaba sobre una peana de ladrillos. Al respecto, véanse González de León, 1839: 18. Montoto, 1983: 66.

${ }^{10}$ González de León, 1839: 18.

11 Tal como evidencia la licencia de obra solicitada por las monjas clarisas al Ayuntamiento el 10 de octubre de 1805. Archivo Histórico Municipal de Sevilla (AHMS), Col. Alfabética, Abecedario de calles, exp. 15/1805. 
dos casas rotuladas con el número 31, inmuebles que fueron reedificados por el maestro de obras Pedro Enríquez hacia el verano de $1807^{12}$. El alzado que trazó Enríquez para la fachada principal del nuevo edificio, que todavía se conserva en el fondo municipal ${ }^{13}$, manifiesta una tipología edilicia muy común en esos primeros años de la centuria que combina bajo porticado sobre columnas y dos pisos altos con vanos y balcones. También hay constancia documental de que el cabildo eclesiástico era "poseedor de varias casas a espalda de la Carnicería Mayor"14, es decir, en los aledaños de la primitiva plaza de la Alfalfa.

El cierre de la vieja carnicería real en la primavera de 1820, a raíz de las nuevas disposiciones higiénicas y de racionalidad distributiva en materia de abastos aprobadas por el Ayuntamiento hispalense en el contexto político del Trienio Liberal, va a tener una enorme repercusión en la formación de la futura plaza de la Alfalfa ${ }^{15}$. La consecuencia directa de la clausura del establecimiento comercial que había definido la economía y sociabilidad del barrio desde su construcción en el siglo XVI fue un acusado vacío de actividad en la zona, que los comerciantes de la Alcaicería de la Loza intentaron paliar solicitando al Gobierno local, el 7 de agosto de 1820 , la reapertura de la carnicería ${ }^{16}$. Para los munícipes sevillanos, no obstante, conocedores del grave deterioro estructural del edificio, el histórico caserón dedicado a la venta de carne ya había dejado de ser operativo. Es más, se había convertido en un serio obstáculo para la fluidez del tránsito viario. La resolución tomada en el cabildo celebrado el 6 de octubre no deja lugar a dudas sobre la intervención urbanística que planeaba llevar a cabo la corporación municipal: se acuerda, con objeto de dar respuesta a la petición de los comerciantes afectados por su cierre, es cierto, que José Echamorros, maestro de obras del Ayuntamiento, elabore un informe técnico sobre el estado en que se encontraba la

${ }_{12} \mathrm{El}$ mal estado de las viviendas fue puesto en conocimiento del Ayuntamiento en abril de 1807, y tras la inspección del arquitecto municipal Félix Caraza, fueron reedificadas por Pedro Enríquez. AHMS, Col. Alfabética, Abecedario de calles, exp. 2/1807.

${ }^{13}$ Fue aprobado por el Gobierno local en julio de 1807. AHMS, Col. Alfabética, Abecedario de calles, exp. 3/1807.

${ }^{14}$ El entonces maestro de obras de la catedral, Fernando Morales, solicita permiso al Ayuntamiento para instalar un balcón en el segundo piso de una de ellas, que fue concedido el 12 de diciembre de 1803, tras el informe favorable de Félix Caraza. AHMS, Col. Alfabética, Abecedario de calles, exp. 25/1803.

${ }^{15}$ En los primeros meses del Trienio Liberal tiene lugar el obligado traslado de todos los vendedores al enorme espacio vacío de la Encarnación, donde se levantará un mercado provisional de madera. Al respecto, véase Fernández González, 2009: 210-211.

${ }^{16}$ Los comerciantes del barrio se quejan al Ayuntamiento de que "por consecuencia de haberse mudado las plazas antiguas a la llamada de la Encarnación y obstruido el tránsito por el cierre de las Carnicerías, han quedado sus establecimientos en la mayor indigencia y miseria por falta de concurrencia”. AHMS, Col. Alfabética, Obras Públicas, caja 830, exp. 74, f. 3r-v. 
carnicería mayor, pero también se le indica a Echamorros que "al mismo tiempo, forme y presente un plano bajo el cual habrán de labrarse edificios a la derecha e izquierda quedando en el centro calle diáfana y recta que comunique desde la Alcaicería hasta la Alfalfa, con el correspondiente señalamiento y medida del terreno que se habrá de labrar, y justiprecio de su valor, así como de los materiales que comprenda" $"$. El encargo del Consistorio hispalense fue culminado por el técnico municipal el 23 de octubre. José Echamorros, tras comprobar que el inmueble tenía muchos tramos "ruinosos y apuntalados para evitar el hundimiento de columnas y arcos", dictamina finalmente que ni "el tránsito" ni "la concurrencia en el establecimiento" debían ser permitidos por el Ayuntamiento ${ }^{18}$.

El proyecto reurbanizador pergeñado por José Echamorros para el terreno ocupado por la antigua carnicería mayor ${ }^{19}$ (Figura 2 ) contempla la apertura de una calle rectilínea y diáfana $\left(\mathrm{n}^{\circ} 5\right)$ con directa comunicación con las dos plazuelas contiguas situadas en sus extremos: al este, la primitiva plaza de la Alfalfa, y al oeste, la de la Verdura, que enlazaba a su vez con la calle Alcaicería de la Loza. A ambos lados de la vía de nueva construcción, distribuidas en dos manzanas rectangulares, cada una con cinco solares edificables, tal como aparece representado en el plano, se proyectaban levantar diez viviendas $\left(n^{\circ} 4\right)$. El planeamiento del maestro mayor del Ayuntamiento también reproduce el tejido urbano adyacente, constituido por el caserío $\left(\mathrm{n}^{\circ} 7\right)$ y el viario que circunvalaban el viejo caserón del siglo XVI dedicado al abasto de carne. De hecho, figuran perfectamente identificadas las calles San Juan, Peladero, Saladero, Odreros y Odrería, esta última muy estrecha y tortuosa, pues estaba afectada por el avance irregular de la vivienda "que era del alcaide de la carnicería mayor" $\left(n^{\circ} 3\right)$. El proyecto, como no podía ser de otra manera, se completaba con el alzado de la fachada principal previsto para las cinco casas de cada manzana (Figura 3). El diseño, muy funcional, concentra la ornamentación edilicia en las columnas dispuestas en los ejes medios de las puertas de entrada, las cornisas voladas de las balconadas y la barroca balaustrada de remate. Para integrar las viviendas resultantes en tamaño, forma y disposición de vanos, Echamorros reitera un esquema modular que consta de bajo, dos pisos de altura y azotea.

La habitual inercia burocrática del Consistorio hispalense ${ }^{20}$ se vio acrecentada por la compleja situación política del país y las gestiones iniciales del proyecto se

${ }^{17}$ AHMS, Col. Alfabética, Obras Públicas, caja 830, exp. 74, ff. 3v-4.

18 AHMS, Col. Alfabética, Obras Públicas, caja 830, exp. 74, ff. 7-8.

19 "El edificio, con inclusión de su muro propio y medianero, resulta estar sobre el área de 16.361 pies cuadrados superficiales de los que rebajados 2.632 que ocupa la calle para el tránsito público, resulta para su venta 13.729 pies y medio cuadrados superficiales". AHMS, Col. Alfabética, Obras Públicas, caja 830, exp. 74, ff. 7-8.

${ }^{20}$ Sobre la ineficacia burocrática de la gestión municipal en el Antiguo Régimen, véase Domínguez León, 1999: 107-108. 
dilataron hasta el 22 de mayo de 1822, fecha en que los munícipes constitucionales del Trienio Liberal ${ }^{21}$ publicaron el preceptivo edicto con la información de obligado cumplimiento, referente al diseño y condiciones de edificación, que debían conocer los posibles adjudicatarios de la obra ${ }^{22}$. Pero ningún promotor se interesó en el plan urbanizador y el concurso quedó finalmente desierto. Dos años más tarde, concretamente el 21 de diciembre de 1824, el programa de intervención aprobado fue reconsiderado por algunos ediles, valorando ya el cabildo municipal la posibilidad de construir un cuartel de caballería en el solar ocupado por la carnicería mayor ${ }^{23}$. Las trazas relacionadas con este nuevo proyecto, que aportan relevante información sobre la estructura del histórico caserón dedicado al abasto de carne ${ }^{24}$, constatan la sencillez del plan previsto por el Ayuntamiento: en los tres pabellones perimetrales que articulaban la planta rectangular del viejo edificio se instalarían los establos de los caballos, y el patio, que abarcaba la sección central de la estructura, se pensaba habilitar como plaza de armas. Las deliberaciones sobre la construcción del establecimiento militar duraron varios años, quizá porque los comerciantes con negocio en la zona seguían insistiendo en la decadencia del barrio y en la necesidad de edificar un "mercado auxiliar de abasto o si esto no fuera posible, que por lo menos se abra una calle recta, lo que favorecerá el tránsito de la Puerta de Carmona a la de Triana"25.

La opinión de Melchor Cano, el nuevo arquitecto municipal, a favor de la remodelación urbanística de este importante sector del casco histórico ${ }^{26}$ será decisiva para que el Gobierno local acabe resolviendo en la sesión de 20 de febrero de 1826 "dividir el terreno de la carnicería vieja en partes regulares para labrar casas colocadas en la calle nueva figurada en el plano" 27 , acuerdo que retomaba el referido proyecto de José Echamorros. De hecho, los solares resultantes se pensaban vender siguiendo la tasación calculada por este maestro de obras municipal en octubre de 1820. Cano consideraba, no obstante, que las viviendas anteriormente

${ }^{21}$ Los ediles liberales, a pesar de las limitaciones económicas del período, lograron mejoras parciales en materia urbanística, especialmente en alumbrado, limpieza y modernización de los abastos. Al respecto, véase Cuenca Toribio, 1991: 41-42.

${ }^{22}$ AHMS, Col. Alfabética, Obras Públicas, caja 830, exp. 74, s. f.

${ }^{23}$ AHMS, Col. Alfabética, Obras Públicas, caja 830, exp. 74, s. f.

${ }^{24}$ Los planos, que se conservan en el Archivo Histórico Municipal de Sevilla, fueron dados a conocer y estudiados por Prada Machuca, 2016: 31-35.

${ }^{25}$ AHMS, Col. Alfabética, Obras Públicas, caja 830, exp. 74, f. 26r-v.

${ }^{26}$ Este arquitecto madrileño, estrecho colaborador del asistente José Manuel Arjona, siempre mostró un profundo interés por el urbanismo, tal como el propio Cano manifiesta en la disertación que escribió con motivo de su nombramiento como académico de mérito de San Fernando. Al respecto, véase Antigüedad Castillo-Olivares, 1990: 417-418, 425 y 433. Su labor como arquitecto del Ayuntamiento de Sevilla en Suárez Garmendia, 1986: 48-54.

${ }^{27}$ AHMS, Col. Alfabética, Obras Públicas, caja 830, exp. 74, s. f. 
planeadas por Echamorros (Figura 3) no eran "suficientemente estéticas", así que diseña el 10 de mayo de 1826 nuevas fachadas para las casas que se proyectaban levantar en el terreno ${ }^{28}$. El alzado de Melchor Cano (Figura 4), arquitectónicamente más riguroso, tiene menos vanos, que están, además, mejor organizados; en vez de un frente unitario, Cano plantea fachadas independientes con ritmos diferentes en las puertas y ventanas de la planta baja, aunque, eso sí, en la disposición de todos los balcones de los pisos altos sigue un similar esquema modular. Otros cambios sustanciales se aprecian en la decoración de la azotea, que ahora, con la sencilla alternancia de pilastras y placas, y ya sin las ornamentales balaustradas que había diseñado José Echamorros, manifiesta una estética más académica y menos barroca.

La intervención viaria propuesta por Echamorros (Figura 2) tampoco fue del agrado de Melchor Cano, hasta el punto de que el arquitecto, el 20 de noviembre, presenta al Ayuntamiento una nueva ordenación del "sitio que ocupa la carnicería vieja y calles adyacentes" (Figura 5). El planeamiento de Cano establece cinco solares edificables más amplios, en vez de los diez propuestos por Echamorros, y cambia la demarcación de la vía de nueva construcción, que ahora se alinea con la embocadura de la calle Alcaicería de la Loza. El programa del arquitecto madrileño garantizaba la directa comunicación de la calle proyectada con la plazuela de la Verdura, pero no con la primitiva plaza de la Alfalfa porque, tal como recoge el documento gráfico, la vivienda que era propiedad de María Luisa Cerero (letras B, C, D, S) y la fuente pública $\left(\mathrm{n}^{\circ} 6\right)$ impedían el enlace. Con todo, reubicar la fuente era fácil y el derribo de casa no parecía muy problemático ${ }^{29}$. La operación urbanística se completaba con la regularización de la calle Odrería, intervención clave que debía llevarse a cabo porque esta vía se situaba paralela a la calle de nueva construcción y facilitaba el tránsito hacia el viario adyacente, constituido por las calles Odreros, Peladero y San Juan. Para ello, como plasma Cano en su proyecto, tendría que ser demolida la vieja y ya abandonada casa del alcaide de la carnicería mayor. Pero la inercia burocrática del Gobierno local paralizó el expediente durante casi cuatro años, hasta el 24 de abril de 1830, fecha en que Manuel de Masa, procurador mayor del Ayuntamiento, redacta un informe

${ }^{28}$ Melchor Cano opinaba que las fachadas debían ajustarse a su nuevo diseño, ya que así se mejoraba la estética de la arquitectura y del barrio, pues, a su juicio, el proyecto de Echamorros "tiene el defecto que se nota en algunos edificios de la ciudad que ofenden la vista del que sepa que la recta distribución entre los vanos y macizos que los separan no solo es muy importante para la solidez de los edificios, sino también necesaria para conseguir su belleza”. AHMS, Col. Alfabética, Obras Públicas, caja 830, exp. 74, s. f.

${ }^{29}$ La propietaria, según explica Melchor Cano al Ayuntamiento, "ha manifestado repetidas veces al maestro Julián de la Vega que no tiene inconveniente en desprenderse de ella siempre que se le dé a cambio otra de igual valor al de la suya". AHMS, Col. Alfabética, Obras Públicas, caja 830, exp. 74, s. f. 
que cuestiona, por razones económicas y funcionales, el plan de alineación que había pergeñado Melchor Cano. Masa consideraba que la vía proyectada no debía ajustarse a la embocadura de la Alcaicería de la Loza porque esta calle era "bastante angosta, por donde no puede pasar carruaje alguno", y plantea -seguramente influido por el proyecto urbanizador de José Echamorros, que sin duda conocía porque, al fin y al cabo, formaba parte del expediente técnico que había estudiado y valorado- su apertura justo por el eje medio del área ocupada por el edificio de la carnicería ya que, con la nueva demarcación, se evitaría la adquisición y posterior demolición de la vivienda de Cerero. Es más, consideraba el procurador municipal que parcelar el terreno en solares pequeños y edificar, a cada lado de la calle nueva, diez casas de reducidas dimensiones con dos pisos de altura por lo menos, además de facilitar la venta de las parcelas, proporcionaría mayores ingresos al Ayuntamiento ${ }^{30}$. Con objeto de tomar una decisión al respecto, los munícipes hispalenses requieren la presencia de Melchor Cano en el cabildo celebrado el 24 de mayo $^{31}$. En su comparecencia, el arquitecto reitera la idoneidad técnica de su proyecto de 1826 y lo vincula, además, con una futura operación urbanística mucho más ambiciosa que propone al Gobierno local: la modernización y mejora del viario comprendido entre la plaza de la Alfalfa y la Puerta de Carmona. Aun reconociendo que las calles en este sector de la ciudad eran "intrincadas y estrechas y no facilitaban el tránsito a los carruajes" ${ }^{32}$, creía Cano que su alineación y ensanche podrían completarse en pocos años. Para ello, según manifiesta el técnico titular a la corporación municipal, habría que desarrollar un programa de intervención centrado inicialmente en dos focos esenciales de actuación: la calle de nueva construcción, cuyo trazado debía ajustarse a la configuración viaria de la Alcaicería de la Loza, tal y como había previsto en su planeamiento de 1826; y la calle Alfalfa, que era preciso regularizar mediante una operación de alineación y ensanche, pues estaba estratégicamente situada entre la plazuela de la Alfalfa y la calle Calabaza y constituía, por tanto, una referencia clave para las siguientes fases ${ }^{33}$.

${ }^{30}$ AHMS, Col. Alfabética, Obras Públicas, caja 830, exp. 74, s. f.

31 AHMS, sección VI, Escribanías de cabildo siglo XIX, tomo 66, exp. 14.

32 En su informe al Ayuntamiento, explica Melchor Cano que "desde dicha Puerta [de Carmona] a la plaza de Pilatos caben los carruajes con comodidad, no tanto por la calle de las Águilas y con dificultad por la de la Calabaza y por la que de ésta va a la plazuela de la Alfalfa". AHMS, sección VI, Escribanías de cabildo siglo XIX, tomo 66, exp. 14.

${ }_{33}$ Según argumenta Cano, "la calle de la Calabaza tiene una de sus aceras con edificios de buena construcción y los de la opuesta están la mayor parte en última vida y por consiguiente podrá ensancharse la calle por este lado. Al salir de la calle de la Calabaza a la de los Mesones se encuentra la esquina de la calle que se dirige a la plaza de la Alfalfa. Esta esquina impide el paso de los carruajes y todas las casas que hay desde ella hasta las casas que se tratan de labrar están en última vida. La alineación pues de las casas nuevas debe ser a la esquina de la calle de la Calabaza y aunque ahora produzca en la alineación 
El Ayuntamiento aceptó finalmente el dictamen de Melchor Cano y un mes más tarde, el 26 de junio de 1830, presenta el arquitecto un primer proyecto de alineación para la calle Alfalfa. La nueva demarcación, no obstante, dio lugar a una controversia en el cabildo municipal, pues muchos ediles consideraban que el plan previsto lesionaba en exceso los intereses legítimos de los propietarios de las fincas afectadas por la medida. Por este motivo, Cano, a finales de agosto, establece un nuevo programa de intervención con tres líneas de fachada posibles. Aunque el documento gráfico se conserva en el Archivo Histórico Municipal de Sevilla $^{34}$, no lo reproduzco por la limitación existente en el número de imágenes. En todo caso, la planimetría del arquitecto madrileño constata una primera alineación que plasma su propuesta inicial: establece una calzada muy ancha que comprende desde la calle Odreros, que es regularizada en su confluencia con la plaza de la Alfalfa, hasta las calles Mesones y Calabaza; una segunda línea de fachada, que es justificada por el propio Melchor Cano explicando "que aunque forma un pequeño ángulo, tiene la ventaja de no dejar tantos entrantes mientras se fuesen labrando las casas situadas en ella"; y una tercera variante, que a pesar de reducir las dimensiones de la futura calle, es tenida en cuenta por el arquitecto porque "deja una entrada cómoda a los carruajes que vengan por la calle de Mesones y de la Calabaza”. Fue precisamente esta última alineación, "por ser la menos perjudicial para los propietarios de las casas", la que se aprobó en el cabildo celebrado el 30 de agosto $^{35}$. Como era de esperar, la regularización de la calle Alfalfa se dilató en el tiempo y el proyecto de Cano fue rectificado al cabo de treinta años por el arquitecto José de la Coba, en cumplimiento de las instrucciones verbales de Balbino Marrón, entonces arquitecto titular del Ayuntamiento. El nuevo programa de alineación para calle que trazaron Coba y Marrón en junio de 1860 contemplaba todavía la utilización del antiguo sistema de empedrado usado en la ciudad, que disponía fajas de losas de Tarifa delante de las fachadas de los edificios. Para mejorar la circulación del tramo viario próximo a las calles Mesones y Cabeza del Rey Don Pedro, fue incrementado en cinco varas el ancho establecido con anterioridad de diez pies y medio ${ }^{36}$. Aprobado por la comisión municipal de Obras Públicas algunos días más tarde, el proyecto de alineación y ensanche fue enviado a Madrid, a la Junta Consultiva de Policía Urbana y

un gran resalto entrante en ellas, ese desaparecerá con el tiempo cuando se vayan labrando las casas contiguas, resultando de esto una calle ancha y alineada". AHMS, sección VI, Escribanías de cabildo siglo XIX, tomo 66, exp. 14.

${ }^{34}$ AHMS, Col. Alfabética, Obras Públicas, caja 830, exp. 74, s. f.

${ }^{35}$ AHMS, sección VI, Escribanías de cabildo siglo XIX, tomo 66, exp. 14.

${ }^{36}$ Estas dos calles eran utilizadas para el tránsito de las mercancías que entraban por la Puerta del Osario, pero también formaban parte del circuito viario que conducía el trigo de la alhóndiga a los embarcaderos. AHMS, Col. Alfabética, Alineaciones, caja 21, exp. 17 , s. f. 
Edificios Públicos del Ministerio de Gobernación del Reino. Después de examinarlo, el órgano consultivo dictamina el 17 de septiembre que aunque "la alineación de esta calle está bien estudiada y bien guardadas las reglas con que deben hacerse esta clase de reformas", se debía tomar terreno de las dos aceras de la calle y ensanchar la vía "hasta los veintiún pies cuatro pulgadas de ancho", medida que facilitaría la doble circulación de los carruajes y mejoraría el enlace con la calle Cabeza del Rey Don Pedro ${ }^{37}$. La comisión de Obras Públicas del Ayuntamiento hispalense, no obstante, en la reunión que celebró el 22 de octubre, resuelve presentar alegaciones al dictamen y solicita a la Junta Consultiva del Ministerio que permita limitar el ensanche "a la acera que hace esquina a la calle Mesones, aun cuando hubiese que ocupar sus fincas en la totalidad", porque así se reduciría el número de propietarios perjudicados ${ }^{38}$, petición que, con algunas indicaciones, es finalmente aceptada ${ }^{39}$. En enero de 1895, esta vez bajo las directrices técnicas del entonces arquitecto titular José Sáez López, se llevó a cabo la rectificación parcial de la línea de fachadas establecida por José de la Coba y Balbino Marrón para la calle Alfalfa ${ }^{40}$.

Volviendo a la historia constructiva de la plaza de la Alfalfa, se debe precisar que el Gobierno local, en septiembre de 1830, seguía estudiando la posible reurbanización del terreno ocupado por la carnicería vieja y pidió a Melchor Cano otro informe sobre el proyecto. Con respecto al emplazamiento de la vía de nueva construcción, el arquitecto madrileño se reiteró en su dictamen previo:

${ }^{37}$ AHMS, Col. Alfabética, Alineaciones, caja 21, exp. 17, s. f.

${ }^{38}$ La comisión municipal, con buen criterio, consideraba que no se debía "repartir la pérdida del terreno particular para convertirlo en vía publica entre las casas de ambas aceras porque entonces quedaría a muchas de ellas una escasísima área casi inaprovechable por ser muy reducida". AHMS, Col. Alfabética, Alineaciones, caja 21, exp. 17, s. f.

39 Tal como recoge la Real Orden de 25 de enero de 1861. Aunque el plano y el proyecto de alineación y ensanche se ajustaba a la normativa vigente, la Junta Consultiva de Policía Urbana y Edificios Públicos del Ministerio de Gobernación del Reino ordena "que en lo sucesivo, para la completa ilustración de esta clase de expediente, se incluyan en los planos de alineaciones de calles los fondos de las casas que las constituyen, formalidad con cuyo dato podrían proyectarse con el debido conocimiento los oportunos trazados de ensanches de las que los necesiten en la virtud de alguna información". AHMS, Col. Alfabética, Alineaciones, caja 21, exp. 17, s. f. El proyecto fue declarado de utilidad pública en el verano de 1867.

${ }^{40}$ Con la nueva alineación, que afectaba únicamente a la acera de los impares, se pretendía mejorar la fluidez del tránsito hacia la calle Águilas. Una vez conseguido el visto bueno de la comisión de Obras Públicas del Ayuntamiento, y al no presentar los vecinos afectados ninguna reclamación al respecto, se aprueba definitivamente el proyecto en el cabildo celebrado el 20 de marzo de 1896. AHMS, Col. Alfabética, Alineaciones, caja 21, exp. 17 , s. f. 
debía ajustarse a la embocadura de la calle Alcaicería de la Loza ${ }^{41}$. Eso sí, modificó su opinión sobre el número de viviendas edificables, tal vez influido por el informe del procurador mayor del Ayuntamiento que hacía hincapié en la rentabilidad económica que suponía la venta de un mayor número de solares, estableciendo ahora Cano un límite de diez casas, la mitad con su fachada orientada a la nueva vía proyectada, y otras tantas hacia la calle Odrería ${ }^{42}$. Pero la intervención urbanística prevista por Melchor Cano, a pesar de los pormenorizados estudios técnicos del arquitecto, nunca se llevó a efecto.

El histórico caserón dedicado a la venta de carne fue dejado a su suerte, hasta el punto de que en su entorno se creó un foco de prostitución ${ }^{43}$. El grave deterioro del edificio y la necesidad de derribarlo sin demora para evitar peligros a la población fue certificado por Cano el 3 de noviembre de 1836, pero hasta octubre de 1837, después de ser apuntalada la "vivienda inmediata propiedad de las monjas de Santa Clara", no fue demolida la carnicería mayor. Con esta operación de derribo, la calle Odrería desapareció del viario de Sevilla y el nuevo solar vacío resultante fue incorporado a la primitiva plazuela de la Alfalfa, formándose, por agregación, un amplio espacio ciudadano con una clara direccionalidad longitudinal en sentido este-oeste. El lugar, sin un uso concreto, fue aprovechado por varios comerciantes para instalar en él un baratillo de ropas usadas y muebles viejos que toleró el Ayuntamiento hasta el 15 de octubre de $1841^{44}$, fecha en la que el regidor Antonio Agustín de Velasco informa a los capitulares sobre el "indecente mercado de trapos y muebles viejos desparramados de forma que impiden y hacen repugnante el tránsito". Para embellecer el lugar, "un borrón para la culta Sevilla", en palabras de Velasco, y rentabilizar económicamente las transacciones realizadas en el espacio público, se debían instalar los vendedores en un adecuado establecimiento comercial, que es descrito por el regidor hispalense como "una línea de puestos de mampostería en una fachada regular y de buen aspecto"45. El entonces arquitecto titular del Ayuntamiento, Ángel de Ayala, se encargará del

${ }^{41}$ Aunque la vía era estrecha en ese momento, en pocos años, a su juicio, podría ser "una de las mejores calles de Sevilla", pues tenía casas ruinosas y antiquísimas que pronto tendrían que ser reedificadas. AHMS, Col. Alfabética, Obras Públicas, caja 830, exp. 74, s. f.

42 “...y debiendo yo proponer a V. E. en todo proyecto el que sea mejor y más cómodo al público insisto siempre en el segundo, debiéndose hacer una calle que sea de seis varas lo menos de ancho, pues descontando dos que ocupan las losas, solo quedan cuatro varas para el paso de carruajes: las casas de seis varas de frente y doce de fondo ofrecen una distribución incómoda, y en las cinco que propongo pueden subdividirse en diez haciendo cinco a la calle nueva y otras tantas a la de la Odrería, mejorándose de ese modo una y otra calle". AHMS, Col. Alfabética, Obras Públicas, caja 830, exp. 74, s. f.

${ }^{43}$ Constan en la documentación varias denuncias vecinales en este sentido desde el 31 de diciembre de 1831. AHMS, Col. Alfabética, Obras Públicas, caja 830, exp. 74, s. f.

${ }^{44}$ Sobre este baratillo de venta diaria, véase González de León, 1839: 35.

${ }^{45}$ AHMS, Col. Alfabética, Obras Públicas, caja 830, exp. 74, s. f. 
diseño ${ }^{46}$, que firma el 13 de noviembre. Dibuja Ayala dos proyectos de fachada que contrastan en su tipo de articulación, pues uno se organiza mediante arcadas y el otro utiliza dinteles de engarce. La estructura de los quince puestos planeados por el arquitecto municipal, no obstante, es similar en ambos casos: consta de sótano abovedado, de entre once y doce pies de alto, piso principal ubicado al nivel de la rasante de la plaza y otra estancia secundaria, "con suelos de buena madera de Flandes", situada a la altura de la línea de imposta de la fachada. Para cubrir el edificio y evitar posibles filtraciones, proyectó Ayala una azotea corrida pavimentada con solería doble ${ }^{47}$.

La construcción del establecimiento comercial no se concreta finalmente y casi cuatro años más tarde, en el cabildo celebrado el 4 de julio de 1846, el Gobierno local resuelve abandonar el proyecto, a pesar del interés que tenía en incrementar sus rentas. La decisión fue tomada a raíz del informe técnico que cuatro meses antes había elaborado Balbino Marrón, nuevo arquitecto titular, desaconsejando la edificación del mercado por la limitación circularia que provocaría la obra en el enlace con la calle Alcaicería. En la sesión municipal se acordó, con todo, adecentar la plaza, pues todos los ediles coincidieron en la necesidad de que "desaparezca el mal aspecto en que se encuentra hoy un punto tan principal de Sevilla" $"$.

El espacio baldío resultante del derribo de la carnicería mayor fue urbanizado, a partir del 19 de enero de 1848, por Balbino Marrón. La historia constructiva de la intervención llevada a cabo por el arquitecto no se puede detallar por falta de datos, pero en los fondos gráficos del archivo municipal se conserva todavía el proyecto de actuación previsto por Marrón para la entonces denominada plaza de las Carnicerías ${ }^{49}$ (Figura 6). En el plano del arquitecto municipal se constatan, al estar perfectamente representadas, las alineaciones programadas para las calles y casas que circunvalaban la plaza proyectada, referencias gráficas que siguen un claro orden geométrico $\left(\mathrm{n}^{\circ} 3,4,5,7,11\right.$ y 12$)$. Pero esta regularización perimetral de la plaza no fue efectiva ni en la etapa de Balbino Marrón como arquitecto titular del Ayuntamiento hispalense ni en todo el siglo XIX, desde luego, porque las planimetrías de los años 1866 y 1885 que he localizado en el archivo municipal (Figuras 7 y 8), a las que me referiré más adelante, muestran similares irregularidades en el viario y el caserío que rodeaban la plaza en esas fechas, salvo en el edificio situado en el flanco oeste, que Marrón (Figura 6) identifica con

${ }^{46}$ Las trazas y la memoria técnica del arquitecto se conservan en el archivo municipal. AHMS, Col. Alfabética, Obras Públicas, caja 830, exp. 74, s. f.

${ }^{47}$ El primer proyecto fue presupuestado por Ángel de Ayala en 92.250 reales y el segundo en 90.000 reales. AHMS, Col. Alfabética, Obras Públicas, caja 830, exp. 74, s. f.

${ }^{48}$ AHMS, Col. Alfabética, Obras Públicas, caja 830, exp. 74, s. f.

49 Recibió el visto bueno del Jefe Superior Político en el oficio del 6 de abril de 1848 . AHMS, Proyectos, Obras y Alineaciones, plano n ${ }^{\circ} 105$. 
el no 11 ("terreno en que se va a edificar"). La intervención urbanística se limitó, por tanto, al paseo central, que en el plano de 1848 aparece representado como un espacio rectangular de recreo, perfectamente alineado, con un arbolado distribuido homogéneamente y con bancos cerrando sus flancos norte y sur. El esquema, muy utilizado en la urbanística española de la etapa de Isabel II, acusa la influencia francesa e inglesa en su formulación ${ }^{50}$. Una década más tarde, con motivo del traslado de la fuente pública de la plaza, que finalmente quedó instalada "al costado de la casa número 6 de la plaza", el arquitecto José de la Coba inspeccionó el área que Balbino Marrón había acondicionado como paseo, así como los terrenos inmediatos ${ }^{51}$.

El fondo documental del Archivo Histórico Municipal de Sevilla conserva algunos croquis y alzados, fechados en los años 60 del siglo XIX, relativos a varias casas ubicadas en la actual plaza de la Alfalfa, entonces denominada del Infante Don Fernando, como la rotulada con el número 7 -donde, por cierto, estaba colocada la placa con el nombre de la plaza-, que fue intervenida bajo planos de José de la $\mathrm{Coba}^{52}$; la finca número 9, que se reformó según el diseño dado por Juan Talavera de la Vega ${ }^{53}$; o la vivienda número 37 de la calle Alfalfa, que daba asimismo hacia la plaza, reedificada también por Talavera en mayo de $1867^{54}$. Pero el documento gráfico sobre la plaza de la Alfalfa más relevante de la década, qué duda cabe, es el proyecto delineado el 12 de noviembre de 1866 por el arquitecto titular Manuel Galiano (Figura 7) con la intención de ordenar los frentes de los edificios que circunvalaban el paseo construido por Balbino Marrón. Si se coteja el plano con el dibujado en 1848 por Marrón (Figura 6) se constatan, en el área central de recreo, la similar distribución del arbolado y la diferente disposición de los bancos, que ahora, en 1866, configura un paseo mejor integrado, menos geométrico y más orgánico. La planimetría de Galiano (Figura 7) mantiene las líneas de fachada establecidas por Balbino Marrón: las viviendas que cerraban el ámbito espacial por el lado sur tenían sus frentes perfectamente alineados, pero las correspondientes al flanco norte debían adelantar sus fachadas tomando

${ }^{50}$ Al respecto, véase Suárez Garmendia, 1980: 239-259; 1986: 166-167.

${ }^{51}$ Según figura presupuestado en una anotación del 28 de agosto de 1858, el traslado de la fuente tuvo un coste de 3.864 reales de vellón. AHMS, Col. Alfabética, Abecedario de calles, exp. 10/1858.

${ }_{52}$ El diseño del arquitecto, que se fecha el 11 de enero de 1860, fue aprobado por la comisión de Obras Públicas el 20 de enero. AHMS, Col. Alfabética, Abecedario de calles, exp. 96/1860.

${ }_{53}$ Los planos, que se datan el 22 de febrero de 1861, recibieron el visto bueno de la comisión de Obras Públicas el 22 de abril. AHMS, Col. Alfabética, Abecedario de calles, exp. 39/1861.

${ }^{54}$ AHMS, Col. Alfabética, Abecedario de calles, exp. 11/1867. Con anterioridad, hacia la primavera de 1858, el edificio había sido reformado por el arquitecto Manuel Galiano. AHMS, Col. Alfabética, Abecedario de calles, exp. 10/1858. 
terreno público. Para el caserío situado en el lado oeste de la plaza proyectó el arquitecto un pequeño retranqueo, modificación de líneas más acusada, por necesidades viarias, en el contiguo esconce que estrangulaba el tránsito hacia la calle Peladero ${ }^{55}$. Según el plan previsto, se establecía para todo el ámbito de la plaza una anchura de 25 metros, aunque la entrada por el lado de la calle Alcaicería alcanzaba los 35 y la correspondiente a la calle Alfalfa se reducía hasta los 24 metros, dimensiones suficientes, en todo caso, para asegurar la cómoda circulación de carruajes en todas direcciones y evitar molestias innecesarias a los ociosos ciudadanos que disfrutaban del suelo de terrizo y los árboles del paseo central, pero también de la fuente pública y el moderno equipamiento de bancos y urinarios $^{56}$. El proyecto de Manuel Galiano, que fue aceptado por el Gobierno local dos semanas más tarde, recibe el visto bueno de Madrid el 3 de enero de 1867 y se aprueba definitivamente en la sesión municipal celebrada el 12 de febrero en el Consistorio hispalense ${ }^{57}$.

La plaza, que fue dedicada en 1868 a Mendizábal, autor de uno de los procesos desamortizadores del siglo XIX, sufrió un cambio drástico en su fisonomía y función ciudadana a finales del ochocientos. De esta intervención urbanística, llevada a cabo en el período en que Francisco Aurelio Álvarez Millán desempeñó el cargo de arquitecto titular del Ayuntamiento, se conserva un significativo documento gráfico, fechado el 1 de septiembre de $1885^{58}$ (Figura 8), que esclarece el alcance de las obras realizadas, presupuestadas en un total de 8.688 pesetas. Con objeto de mejorar la circulación del ya intenso tráfico rodado que atravesaba el centro de Sevilla, fue demolido el paseo central de la plaza. El enlosado, los árboles, la fuente, el urinario, los bancos y los puestos de agua se levantaron y en el terreno se construyó una calzada de hormigón pavimentada con adoquines. Para mantener cierto perfil peatonal, eso sí, fueron edificadas amplias aceras y en ellas se plantaron árboles. En febrero de 1886, con los trabajos ya rematados, los munícipes, que consideraban los quioscos estéticos y cómodos para el vecindario, permiten la reubicación de los cuatro puestos de agua en las nuevas aceras ${ }^{59}$.

${ }^{55}$ La finca número 3 se reformó según el plano presentado el 23 de noviembre de 1868 por el maestro de obras Antonio Rodríguez Real, intervención autorizada semanas más tarde por la comisión municipal de Ornato. La estrechez viaria que impedía el tránsito fluido hacia la calle Peladero no fue finalmente reformada, tal como constata un plano de 1885 (Figura 8), ya con Francisco Aurelio Álvarez Millán como arquitecto titular del Ayuntamiento. AHMS, Col. Alfabética, Abecedario de calles, exp. 123/1868.

${ }_{56}$ AHMS, Col. Alfabética, Alineaciones, caja 23, exp. 39, s. f.

${ }^{57}$ El proyecto fue expuesto por espacio de veinte días en las oficinas municipales, pero no se presentaron alegaciones. AHMS, Col. Alfabética, Alineaciones, caja 23, exp. 39, s. f.

${ }_{58}$ AHMS, Col. Alfabética, Paseos, caja 540, exp. 104, s. f.

59 AHMS, Col. Alfabética, Paseos, caja 540, exp. 104, s. f. Simultáneamente a esta intervención en la plaza, concretamente el 31 de diciembre de 1885, se inician sendos expedientes de alineación de la calle de la Alhóndiga y la de Cabeza del Rey Don Pedro que 
La nueva documentación localizada sobre la plaza de la Alfalfa y su viario aledaño ha permitido historiar las transformaciones sufridas por este importante ámbito de sociabilidad del casco histórico de Sevilla en el siglo XIX. Se han dado a conocer y estudiado las intervenciones urbanísticas llevadas a cabo por los arquitectos Balbino Marrón, quien a partir de 1848 configuró la morfología del espacio vacío resultante del derribo del edificio de la carnicería mayor, Manuel Galiano y Francisco Aurelio Álvarez Millán. Pero también se han analizado los proyectos del Ayuntamiento hispalense relativos a la construcción de un cuartel de caballería o un nuevo mercado, así como los planeamientos urbanísticos del maestro de obras José Echamorros y el arquitecto Melchor Cano. La investigación realizada, en definitiva, ha supuesto un avance en el conocimiento de esta emblemática plaza de Sevilla.

Fecha de recepción: 9 de septiembre de 2019

Fecha de aceptación: 23 de febrero de 2020

\section{BIBLIOGRAFÍA}

Antigüedad del Castillo-Olivares, María Dolores (1990): "El arquitecto Melchor Cano y la teoría de la ciudad". En: Espacio, Tiempo y Forma. Serie VII, 4, pp. 417-439.

Albardonedo Freire, Antonio José (2002): El urbanismo de Sevilla durante el reinado de Felipe II. Sevilla: Guadalquivir Ediciones.

Blanco Freijeiro, Antonio (1979): Historia de Sevilla. La ciudad antigua (de la Prehistoria a los visigodos). Sevilla: Universidad de Sevilla.

Campos, Juan Manuel (1993): "La estructura urbana de la colonia Iulia Romula Hispalis en época imperial". En: Anales de Arqueología Cordobesa, 4, pp. 181-219.

Collantes de Terán Sánchez, Antonio (1977): Sevilla en la Baja Edad Media. La ciudad y sus hombres. Sevilla: Ayuntamiento de Sevilla.

Collantes, Antonio/Cruz, Josefina/Reyes, Rogelio/Rodríguez, Salvador (1993): Diccionario histórico de las calles de Sevilla. Sevilla: Consejería de Obras Públicas y Transportes, tomo I.

Cuenca Toribio, José Manuel (1991): Historia de Sevilla. El siglo XIX (del Antiguo al Nuevo Régimen). Sevilla: Universidad de Sevilla.

De Morgado, Alonso (1587): Historia de Sevilla. Sevilla: Andrea Pescioni y Juan de León.

fueron aprobados en el cabildo municipal del 3 de marzo de 1886 y ejecutados por el arquitecto Francisco Aurelio Álvarez Millán. AHMS, Col. Alfabética, Alineaciones, caja 31, exp. 222 , s. f. 
De Peraza, Luis (1996): Historia de Sevilla (ms., 1536-1537). Sevilla: Asociación Amigos del Libro Antiguo.

Domínguez León, José (1999): La sociedad sevillana en la época isabelina. Córdoba: CajaSur.

Fernández González, Alberto (2009): "Arquitectura y urbanismo en la Sevilla ochocentista: la plaza-mercado de la Encarnación". En: Anuario del Departamento de Historia y Teoría del Arte, 21, pp. 205-222.

González Acuña, Daniel (2011): Forma Urbis Hispalensis. El urbanismo de la ciudad romana de Hispalis a través de los testimonios arqueológicos. Sevilla: Universidad de Sevilla/Fundación Focus-Abengoa.

González de León, Félix (1839): Noticia histórica del origen de los nombres de las calles de la ciudad de Sevilla. Sevilla: Imprenta de José Morales.

Montoto, Santiago (1983): Esquinas y conventos de Sevilla. Sevilla: Universidad de Sevilla.

Prada Machuca, Manuel Alejandro (2016): Arquitectura y Ciudad en la Sevilla del siglo XIX: Mercados y Plazas de abasto. Trabajo de Fin de Máster Universitario en Patrimonio Artístico Andaluz y su Proyección Iberoamericana. Sevilla: Facultad de Geografía e Historia de la Universidad de Sevilla.

Suárez Garmendia, José Manuel (1980): "La formación de plazas en Sevilla a mediados del XIX". En: Archivo Hispalense, 192, pp. 239-259.

(1986): Arquitectura y urbanismo en la Sevilla del siglo XIX. Sevilla: Diputación Provincial de Sevilla.

Vioque Cubero, R./Vera Rodríguez, I. M./López López, N. (1987): Apuntes sobre el origen y evolución morfológica de las plazas del casco histórico de Sevilla. Sevilla: Ayuntamiento de Sevilla/Junta de Andalucía. 


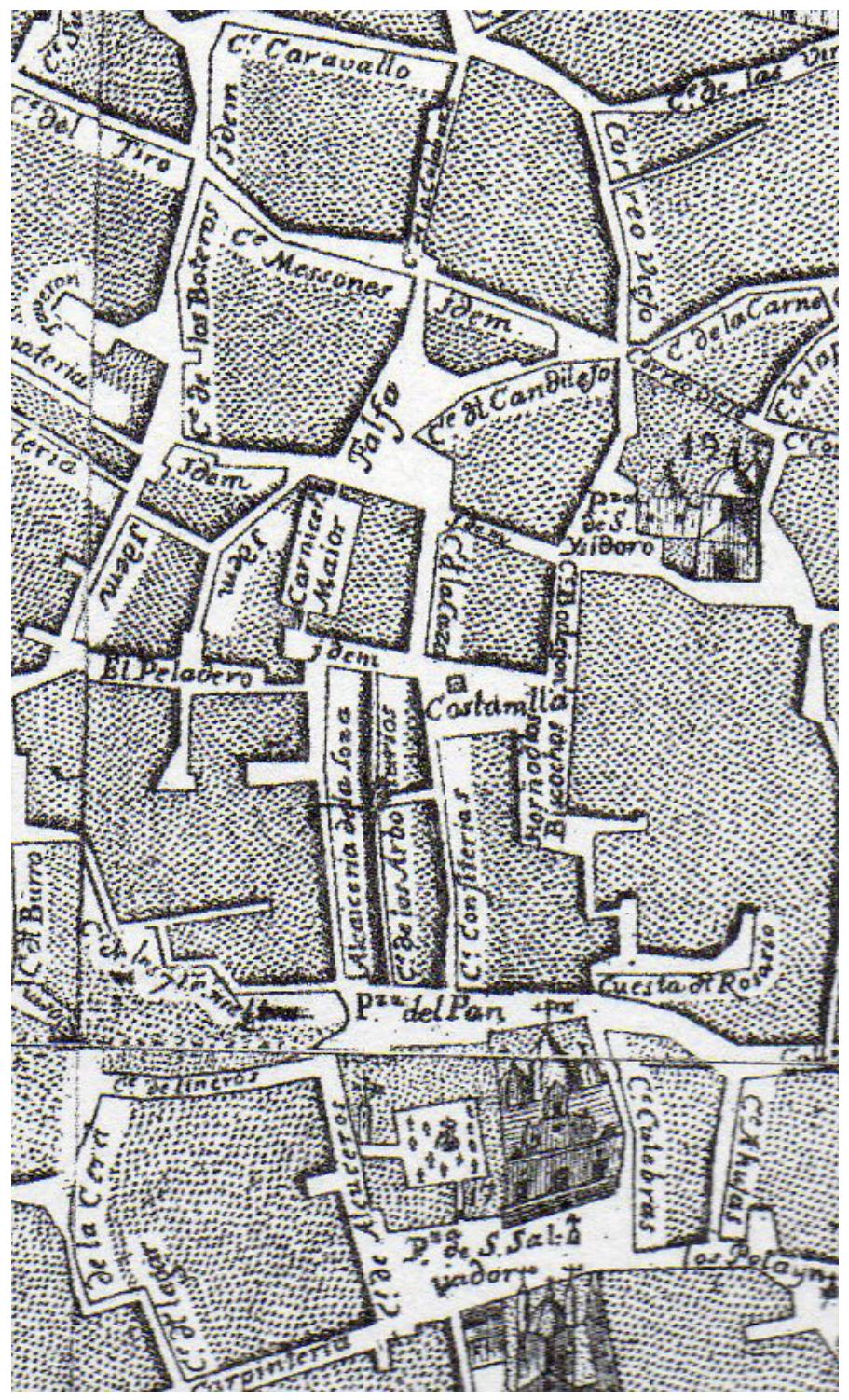

Figura 1. F. Coelho y J. Amat, Plano de Sevilla del asistente Pablo de Olavide, 1771, AHMS. 


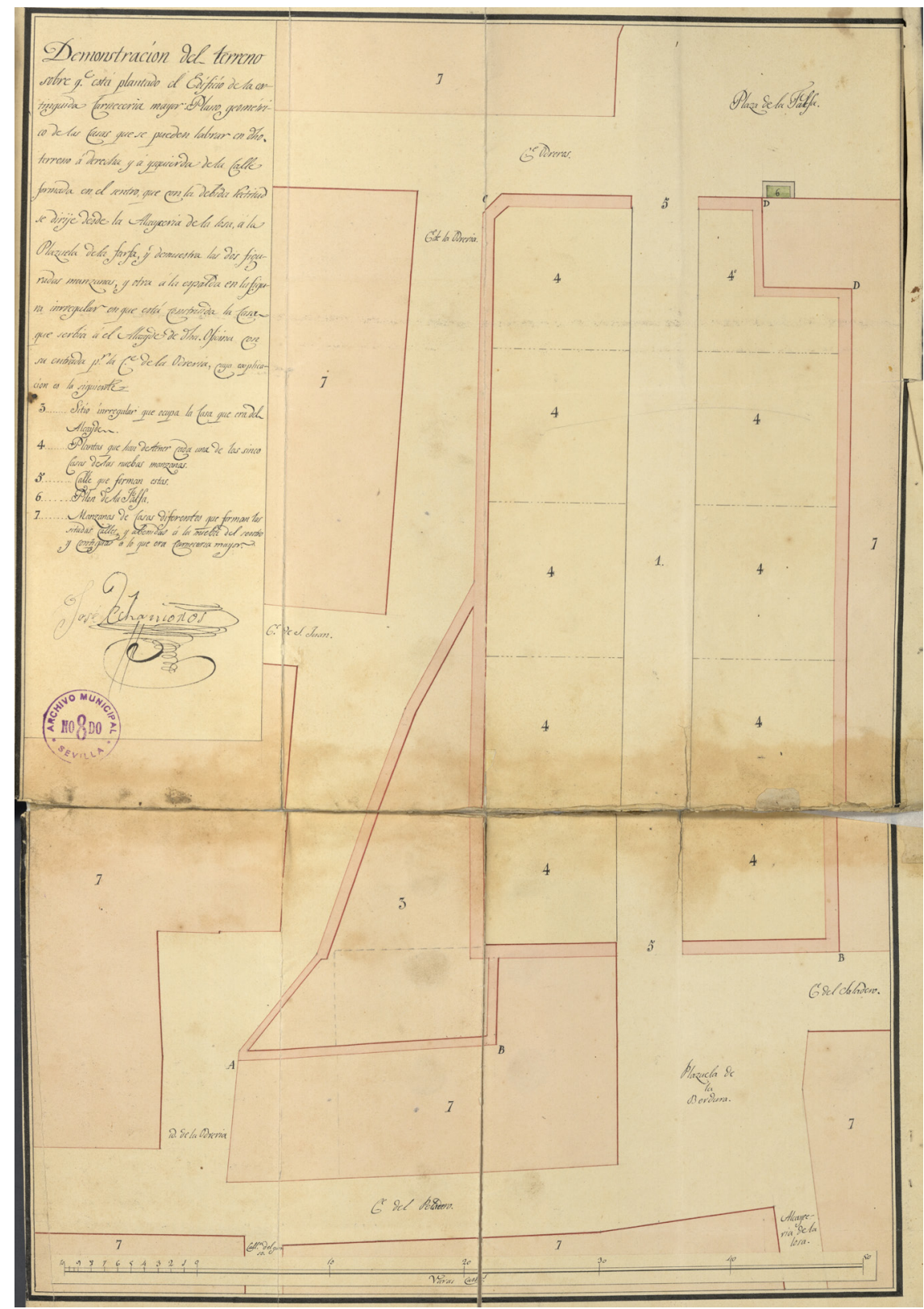

Figura 2. José Echamorros, Proyecto de urbanización para el solar de la Carnicería Mayor: planta, 1820, AHMS. 


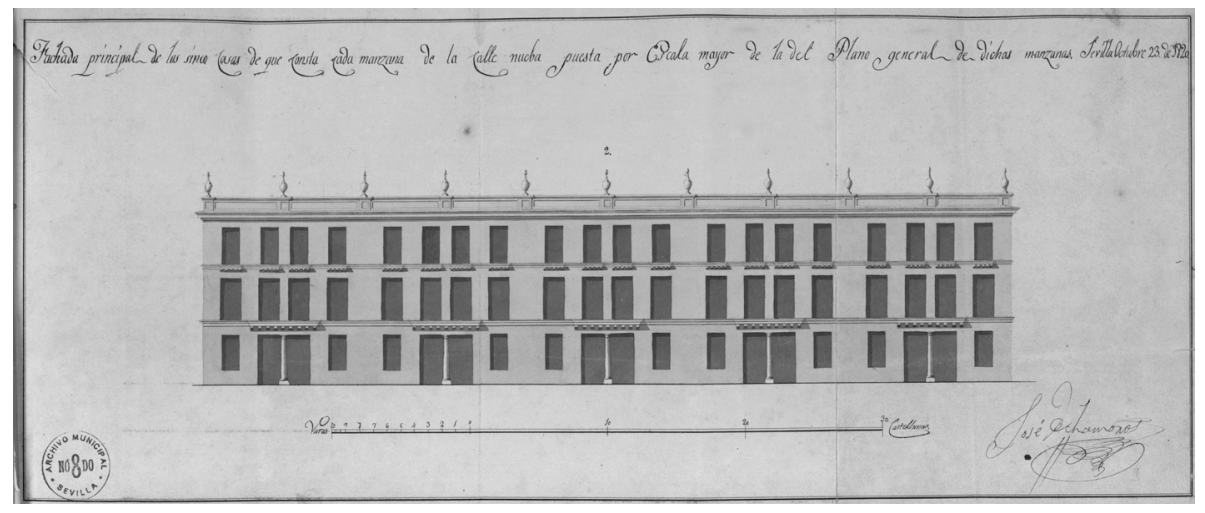

Figura 3. José Echamorros, Proyecto de urbanización para el solar de la Carnicería Mayor: alzado, 1820, AHMS. 


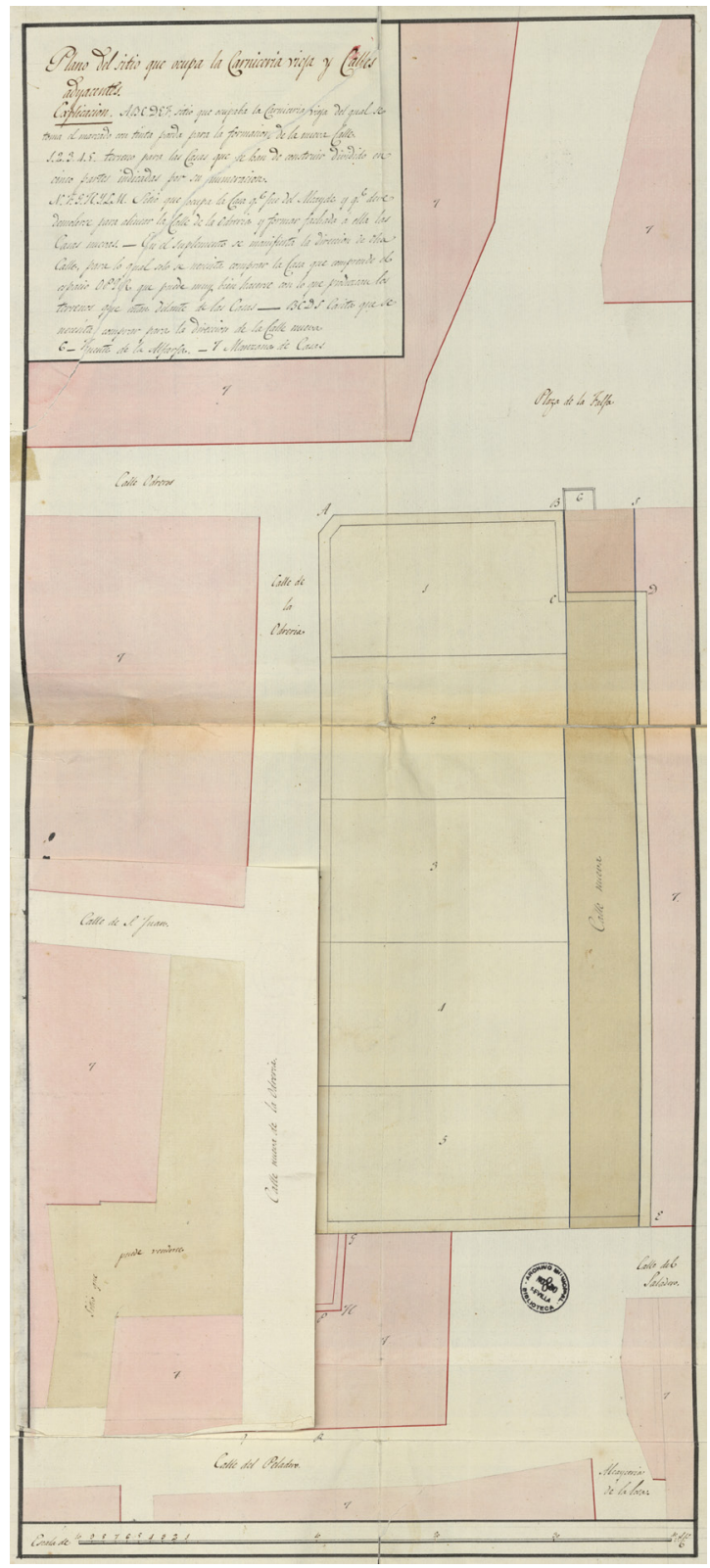

Figura 4. Melchor Cano, Proyecto de urbanización para el solar de la Carnicería Mayor: planta, 1823, AHMS. 


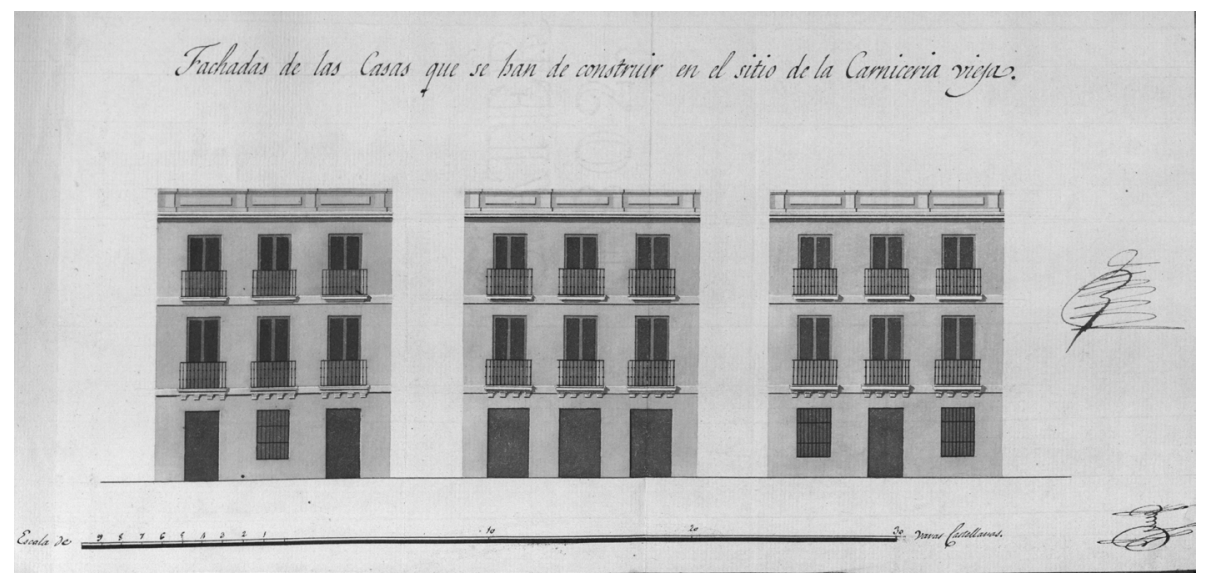

Figura 5. Melchor Cano, Proyecto de urbanización en el solar de la Carnicería Mayor: alzado, 1823, AHMS. 


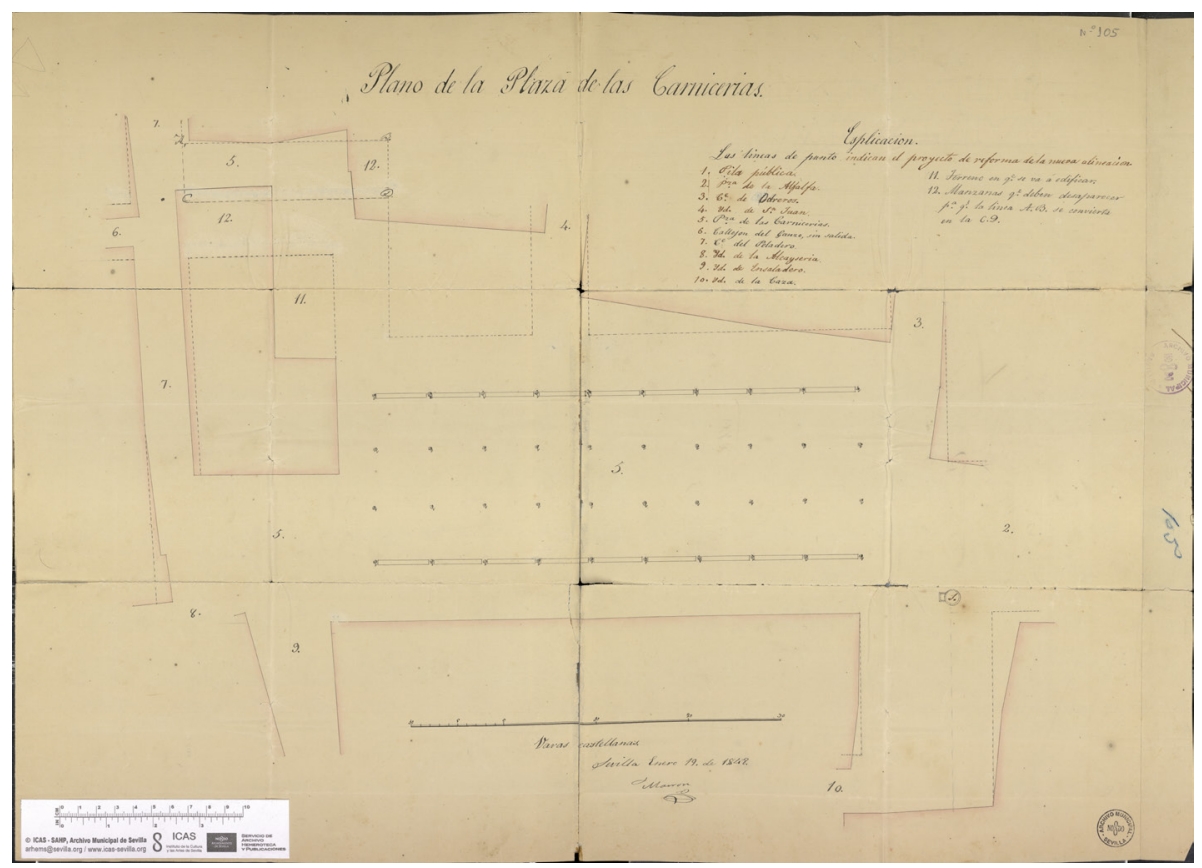

Figura 6. Balbino Marrón, Proyecto de regularización para la plaza de las Carnicerías, 1848, AHMS. 


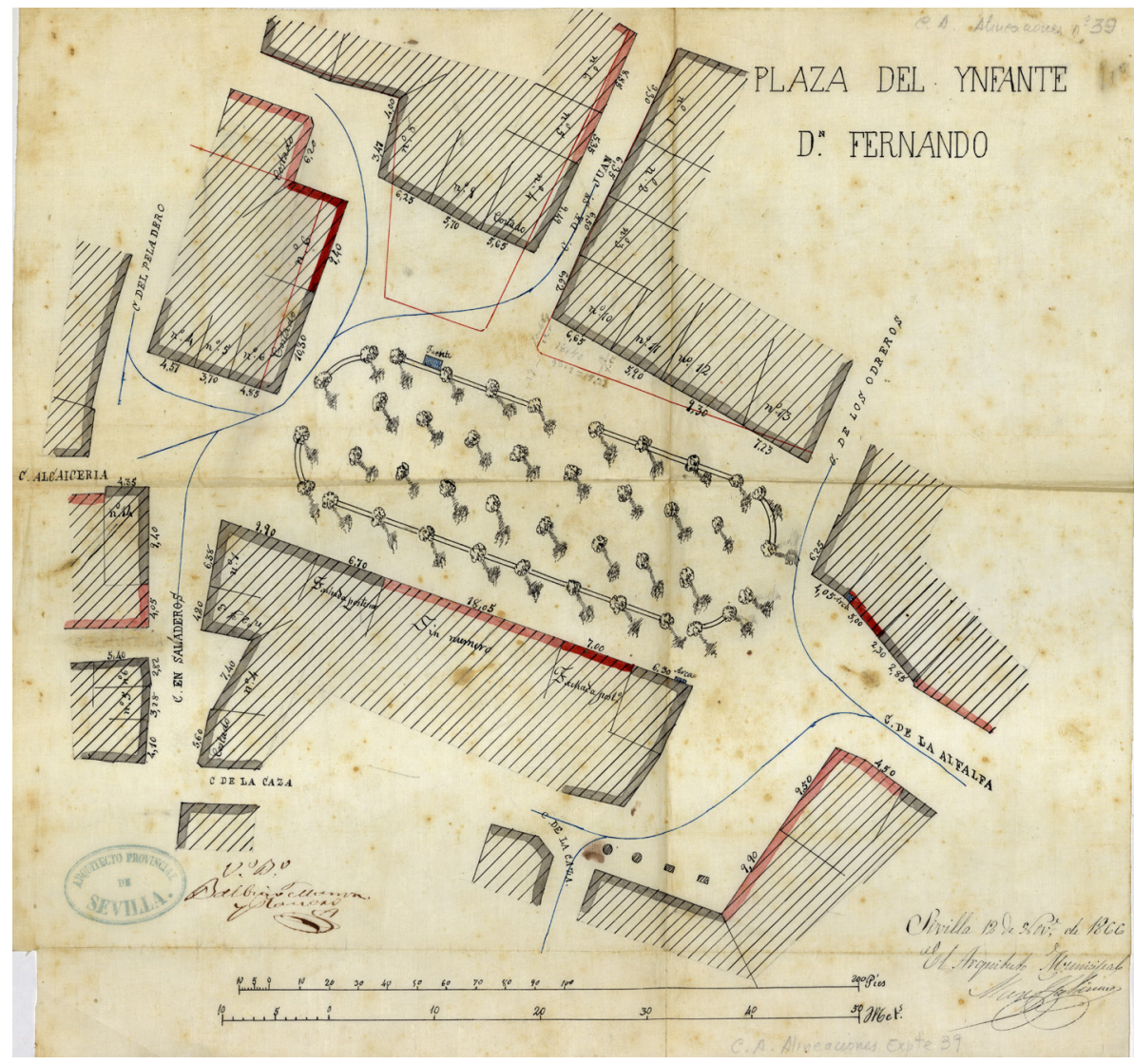

Figura 7. Manuel Galiano, Proyecto de urbanización de la plaza del Infante Don Fernando, 1866, AHMS. 


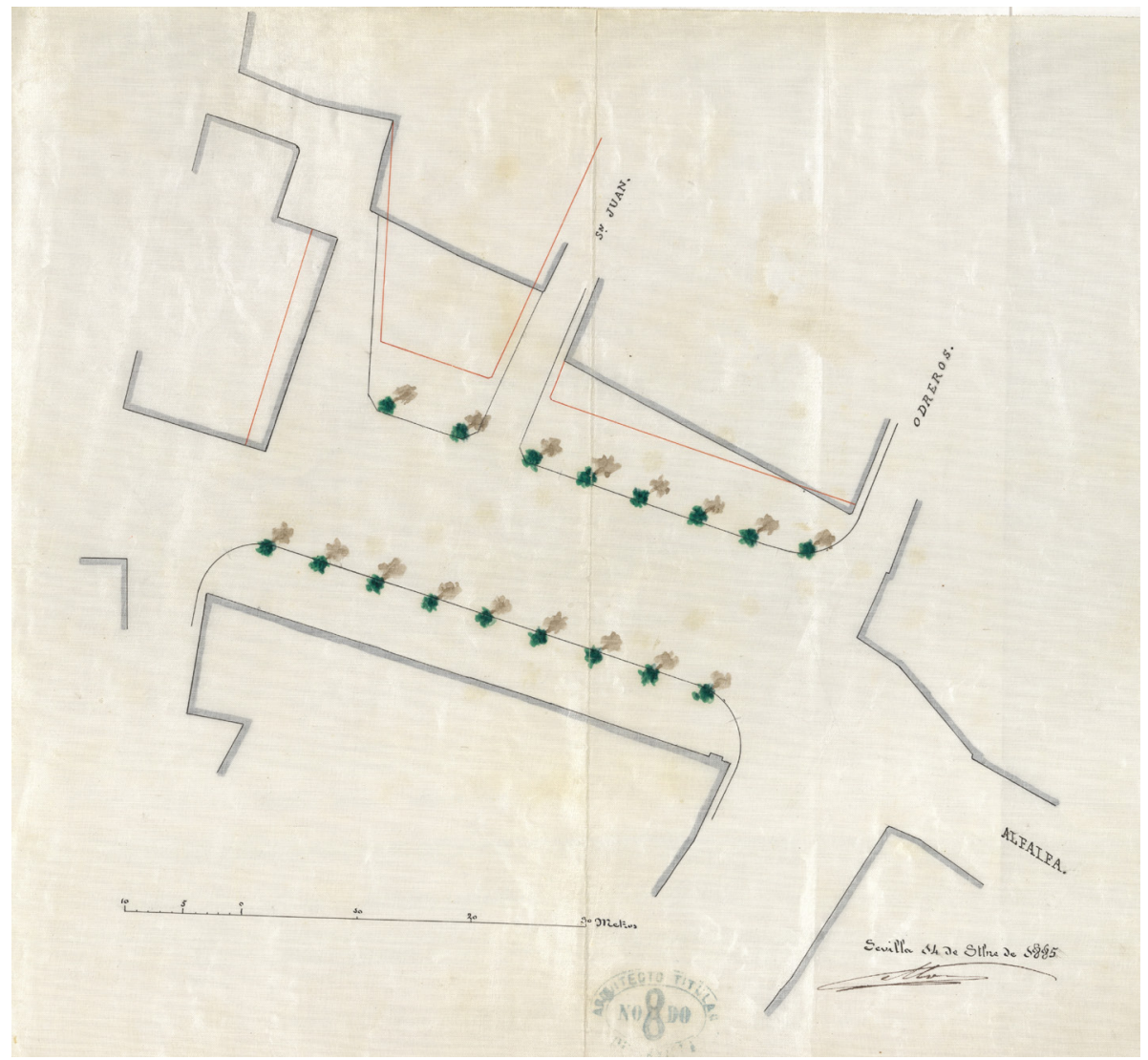

Figura 8. F. A. Álvarez Millán, Proyecto de remodelación de la plaza de Mendizábal, 1885, AHMS. 